\title{
Proteomic analysis of human follicular fluid associated with successful in vitro fertilization
}

Xiaofang Shen ${ }^{1,2^{*}+}$, Xin Liu $^{1 \dagger}$, Peng Zhu ${ }^{1 \dagger}$, Yuhua Zhang ${ }^{3+}$, Jiahui Wang ${ }^{1+}$, Yanwei Wang ${ }^{1}$, Wenting Wang ${ }^{1}$, Juan Liu', Ning Li ${ }^{1}$ and Fujun Liu ${ }^{1 *}$

\begin{abstract}
Background: Human follicular fluid (HFF) provides a key environment for follicle development and oocyte maturation, and contributes to oocyte quality and in vitro fertilization (IVF) outcome.

Methods: To better understand folliculogenesis in the ovary, a proteomic strategy based on dual reverse phase high performance liquid chromatography (RP-HPLC) coupled to matrix-assisted laser desorption/ionization time-offlight tandem mass spectrometry (LC-MALDI TOF/TOF MS) was used to investigate the protein profile of HFF from women undergoing successful IVF.

Results: A total of 219 unique high-confidence (False Discovery Rate (FDR) < 0.01) HFF proteins were identified by searching the reviewed Swiss-Prot human database (20,183 sequences), and MS data were further verified by western blot. PANTHER showed HFF proteins were involved in complement and coagulation cascade, growth factor and hormone, immunity, and transportation, KEGG indicated their pathway, and STRING demonstrated their interaction networks. In comparison, 32\% and 50\% of proteins have not been reported in previous human follicular fluid and plasma.

Conclusions: Our HFF proteome research provided a new complementary high-confidence dataset of folliculogenesis and oocyte maturation environment. Those proteins associated with innate immunity, complement cascade, blood coagulation, and angiogenesis might serve as the biomarkers of female infertility and IVF outcome, and their pathways facilitated a complete exhibition of reproductive process.
\end{abstract}

Keywords: Human follicular fluid, in vitro fertilization, LC-MALDI TOF/TOF MS, Folliculogenesis, Bioinformatics

\section{Background}

In vitro fertilization (IVF) coupled with embryo transfer into uterus has been applied as treatment for infertility several decades. IVF was initially used to assist the reproduction of sub-fertile women caused by tubal factors [1]. With the improvement of IVF techniques, IVF is now a routine treatment for many reproductive diseases. However, the success rate of pregnancy is still a problem in clinical IVF practice, which is only about $50 \%$ even if the embryos with normal morphology were

\footnotetext{
* Correspondence: 18615023865@163.com; Ifjyt@126.com

${ }^{\dagger}$ Equal contributors

${ }^{1}$ Central Laboratory, The Affiliated Yantai Yuhuangding Hospital of Qingdao

University, Yantai 264000, Shandong, People's Republic of China

Full list of author information is available at the end of the article
}

used for transfer [2]. In order to select embryos with the best potential good for IVF outcome, morphological assessments of blastocyst and blastocoels have been adopted, but it was still difficult to predict the quality of embryos [3]. Therefore, it was necessary to develop new strategies for embryo quality evaluation. Epidemiologic investigations showed that many intrinsic and extrinsic factors contributed to the quality of embryo. Because oocyte quality directly influences embryo development, HFF (microenvironment of oocyte maturation) became a main factor contributing to the success of IVF treatment [4].

Small antral follicles respond to ovarian stimulation by increasing in size due to rapid accumulation of follicular fluid, as well as granulosa cell divisions, which necessitate follicular basal lamina expansion. The components 
of HFF had several origins: secretions from granulosa cells, thecal cells, occytes, and blood plasma composition transferred through the thecal capillaries [5]. The major components of HFF were proteins [6], steroid hormones [7], and metabolites [8]. HFF provided a special milieu to facilitate the communications between occyte and follicular cells, the development of follicle and the maturation of occytes. The alteration of HFF proteins reflected disorders of main secretary function of granulosa cells and thecae, and the damage of blood follicular barrier, which was associated with abnormal folliculogenesis [9] and a diminished reproductive potential [10]. In IVF treatment, HFF was easily accessible during the aspiration of oocytes from follicle, and was an ideal source for noninvasive screening of biomakers for oocyte maturation, fertilization success, IVF outcome, pregnancy, and ovarian diseases.

In the postgenomic era, proteomic techniques have been widely used in the field of reproductive medicine. HFF proteome has become a hotspot for research, which not only contributed to discovering proteins related to IVF outcomes, but also improved our comprehensive understanding of physiological process during follicle development and oocyte maturation [11]. Li and co-workers used surface-enhanced laser desorption/ionization-time of flight-mass spectrometry (SELDI-TOF-MS) combined with weak cation-exchange protein chip (WCX-2) to search for differentially expressed HFF proteins from mature and antral follicles [12]. Two-dimensional gel electrophoresis (2D-GE) followed by matrix-assisted laser desorption/ionization time-of-flight mass spectrometry (MALDI-TOF MS) was also used to identify 8 differentially expressed HFF proteins related to immune and inflammatory responses from controlled ovarian hyperstimulation $(\mathrm{COH})$ and natural ovulatory cycles [13]. Ambekar and co-workers carried out SDS-PAGE, OFFGEL and SCX-based separation followed by LC-MS/MS analysis to characterize 480 HFF proteins for a better understanding of folliculogenesis physiology [14]. Chen and co-workers explored the HFF biomarkers between successfully fertilized oocytes and unfertilized mature oocytes through nano-scale liquid chromatography coupled to tandem mass spectrometry (nano LC-MS/MS), and found 53 peptides to be potential candidates [15]. Although proteomic researches on HFF deepened our understanding of reproductive process and provided candidates related to oocyte quality, follicle development, IVF outcome and ovarian disorders, it was still essential to fully delineate the HFF networks and pathways involved in the physiology of reproduction and pathophysiology of infertility.

In the present study, we carried out an in-depth proteomic analysis of HFF from women undergoing successful IVF based on dual RP-HPLC coupled to MALDI
TOF/TOF MS. The results profiled candidate biomarkers for the prediction of oocyte maturation, fertilization, and pregnancy and provided a new complement for HFF dataset, which will improve the understanding of biological processes and complicated pathways and interaction networks in HFF.

\section{Methods}

\section{Patients enrollment and sample preparation}

The HFF samples were collected from 10 women who underwent IVF treatment and achieved pregnancy. The selected patients met the following criteria: infertility not caused by tubal factor; aged less than 38 years; serum FSH values $<12 \mathrm{mIU} / \mathrm{mL}$; undergoing their first fresh egg retrieval cycle; ovulation stimulated with the long protocol. The patients were also without chromosomal abnormalities, polycystic ovary syndrome (PCOS), endometriosis and or endocrine disease. Cause of infertility was simple male factor. The body mass index (BMI) of patients met the normal criteria proposed by WGOC $\left(18.5 \leq \mathrm{BMI} \leq 23.9 \mathrm{~kg} / \mathrm{m}^{2}\right)$ [16-18]. Ovarian stimulation and oocyte retrieval were performed as previously described [19]. Briefly, when more than two follicles exceeded $18 \mathrm{~mm}$ in diameter, 10,000 IU of HCG (Merck Serono, Swiss) was injected intramuscular. After $36 \mathrm{~h}$, HFF was collected during trans-vaginal ultrasound guided aspiration of oocytes. The resultant HFF samples were macroscopically clear and without contamination of the flushing medium.

The samples were centrifuged at $10,000 \times \mathrm{g}$ at $4{ }^{\circ} \mathrm{C}$ for 30 min to produce cell debris-free HFF fraction for further analysis. Concentration of HFF was determined by the Bradford method [20]. This work has been approved by the Ethics Committee of Beijing BaoDao Obstetrics and Gynecology Hospital, and written informed consents were obtained from all participants.

\section{First dimension high pH RP chromatography}

Equal amounts $(50 \mu \mathrm{g})$ of HFF proteins from each sample were pooled for separation. The samples were sequentially treated with $20 \mathrm{mM}$ dithiothreitol at $37{ }^{\circ} \mathrm{C}$ for $120 \mathrm{~min}$, and $50 \mathrm{mM}$ iodoacetamide in dark for $60 \mathrm{~min}$ at room temperature. Then the sample was finally digested using trypsin (sequencing grade, Promega, France) ( $W / \mathrm{W}, 1: 50$ enzyme/protein) overnight at $37^{\circ} \mathrm{C}$. According to the previous method with appropriate modification [21], the first dimension RP separation was performed on PF-2D HPLC System (Rigol) by using a Durashell RP column $(5 \mu \mathrm{m}, 150 \AA, 250 \mathrm{~mm} \times 4.6 \mathrm{~mm}$ i.d., Agela). Mobile phases A ( $2 \%$ acetonitrile, adjusted $\mathrm{pH}$ to 10.0 using $\left.\mathrm{NH}_{3} \cdot \mathrm{H}_{2} \mathrm{O}\right)$ and $\mathrm{B}(98 \%$ acetonitrile, adjusted $\mathrm{pH}$ to 10.0 using $\mathrm{NH}_{3} \cdot \mathrm{H}_{2} \mathrm{O}$ ) were used to develop a gradient. The solvent gradient was set as follows: $5 \% \mathrm{~B}$, 5 min; 5-15\% B, 15 min; $15-38 \%$ B, 15 min; 38-90\% B, 
Table 1 A list of 219 identified high-confidence HFF proteins from women underwent successful IVF by LC MALDI TOF/TOF mass spectrometry (FDR < 0.01)

\begin{tabular}{|c|c|c|c|c|c|c|c|c|}
\hline \multirow[t]{2}{*}{ No } & \multirow[t]{2}{*}{ SwissProt AC } & \multirow[t]{2}{*}{ Name protein description } & \multirow{2}{*}{$\begin{array}{l}\text { Gene } \\
\text { Name }\end{array}$} & \multirow{2}{*}{$\begin{array}{l}\text { Molecular } \\
\text { Weight }\end{array}$} & \multicolumn{2}{|l|}{ experiment 1} & \multicolumn{2}{|l|}{ experiment 2} \\
\hline & & & & & Coverage(\%) & $\begin{array}{l}\text { Matched } \\
\text { Peptides } \\
\text { number }\end{array}$ & Coverage(\%) & $\begin{array}{l}\text { Matched } \\
\text { Peptides } \\
\text { number }\end{array}$ \\
\hline 1 & P43652 & Afamin & AFM & 69,069 & 31.9 & 10 & 35.7 & 10 \\
\hline 2 & P02763 & Alpha-1-acid glycoprotein 1 & ORM1 & 23,512 & 40.8 & 17 & 40.8 & 15 \\
\hline 3 & P19652 & Alpha-1-acid glycoprotein 2 & ORM2 & 23,603 & 45.8 & 15 & 53.2 & 15 \\
\hline 4 & P01011 & Alpha-1-antichymotrypsin & SERPINA3 & 47,651 & 53 & 15 & 44.2 & 16 \\
\hline 5 & P01009 & Alpha-1-antitrypsin & SERPINA1 & 46,737 & 62.7 & 86 & 64.4 & 76 \\
\hline 6 & P04217 & Alpha-1B-glycoprotein & $\mathrm{A} 1 \mathrm{BG}$ & 54,254 & 39.8 & 17 & 48.5 & 19 \\
\hline 7 & P08697 & Alpha-2-antiplasmin & SERPINF2 & 54,566 & 29.1 & 9 & 47.1 & 11 \\
\hline 8 & P02765 & Alpha-2-HS-glycoprotein & AHSG & 39,325 & 42.8 & 14 & 55.9 & 18 \\
\hline 9 & P01023 & Alpha-2-macroglobulin & $\mathrm{A} 2 \mathrm{M}$ & 163,291 & 46.8 & 47 & 47.4 & 46 \\
\hline 10 & P48728 & Aminomethyltransferase, mitochondrial & AMT & 43,946 & 2.2 & 1 & - & - \\
\hline 11 & P01019 & Angiotensinogen & AGT & 53,154 & 37.7 & 14 & 25.8 & 11 \\
\hline 12 & С9JTQ0 & $\begin{array}{l}\text { Ankyrin repeat domain-containing } \\
\text { protein } 63\end{array}$ & ANKRD63 & 39,620 & 15 & 1 & - & - \\
\hline 13 & P01008 & Antithrombin-III & SERPINC1 & 52,602 & 61.9 & 21 & 54.7 & 24 \\
\hline 14 & P02647 & Apolipoprotein A-I & APOA1 & 30,778 & 73.8 & 67 & 82.4 & 69 \\
\hline 15 & P02652 & Apolipoprotein A-II & APOA2 & 11,175 & 70 & 9 & 64 & 9 \\
\hline 16 & P06727 & Apolipoprotein A-IV & APOA4 & 45,399 & 67.2 & 24 & 63.1 & 25 \\
\hline 17 & P02654 & Apolipoprotein C-I & $\mathrm{APOC} 1$ & 9332 & 26.5 & 3 & 37.4 & 3 \\
\hline 18 & P02655 & Apolipoprotein C-II & APOC2 & 11,284 & 39.6 & 2 & 50.5 & 3 \\
\hline 19 & P02656 & Apolipoprotein C-III & APOC3 & 10,852 & 34.3 & 2 & 51.5 & 6 \\
\hline 20 & P05090 & Apolipoprotein D & APOD & 21,276 & 24.9 & 3 & 28.6 & 3 \\
\hline 21 & P02649 & Apolipoprotein E & APOE & 36,154 & 43.2 & 6 & 43.5 & 4 \\
\hline 22 & Q13790 & Apolipoprotein F & APOF & 35,399 & - & - & 8 & 1 \\
\hline 23 & O95445 & Apolipoprotein M & APOM & 21,253 & 26.6 & 2 & 30.3 & 2 \\
\hline 24 & Q9H2U1 & ATP-dependent RNA helicase DHX36 & $\mathrm{DHX36}$ & 114,760 & - & - & 17.9 & 1 \\
\hline 25 & O75882 & Attractin & ATRN & 158,537 & 15 & 1 & - & - \\
\hline 26 & P98160 & $\begin{array}{l}\text { Basement membrane-specific heparan } \\
\text { sulfate proteoglycan core protein }\end{array}$ & HSPG2 & 468,830 & 30.8 & 43 & 31 & 46 \\
\hline 27 & P02749 & Beta-2-glycoprotein 1 & $\mathrm{APOH}$ & 38,298 & 51 & 15 & 41.5 & 16 \\
\hline 28 & Q96KN2 & Beta-Ala-His dipeptidase & CNDP1 & 56,706 & 18.9 & 1 & - & - \\
\hline 29 & P43251 & Biotinidase & BTD & 61,133 & 9.2 & 2 & 14.2 & 1 \\
\hline 30 & Q7L273 & BTB/POZ domain-containing protein KCTD9 & KCTD9 & 42,567 & - & - & 30.1 & 1 \\
\hline 31 & P04003 & C4b-binding protein alpha chain & C4BPA & 67,033 & 11.9 & 2 & 27 & 4 \\
\hline 32 & Q96/Y4 & Carboxypeptidase B2 & CPB2 & 48,424 & 13 & 2 & 16.1 & 2 \\
\hline 33 & P22792 & Carboxypeptidase $\mathrm{N}$ subunit 2 & CPN2 & 60,557 & - & - & 10.8 & 2 \\
\hline 34 & Q9ULM6 & CCR4-NOT transcription complex subunit 6 & CNOT6 & 63,307 & - & - & 2.3 & 1 \\
\hline 35 & Q8N8E3 & Centrosomal protein of $112 \mathrm{kDa}$ & CEP112 & 112,749 & 17.4 & 1 & - & - \\
\hline 36 & Q5SW79 & Centrosomal protein of $170 \mathrm{kDa}$ & CEP170 & 175,293 & - & - & 5.9 & 1 \\
\hline 37 & P00450 & Ceruloplasmin & $C P$ & 122,205 & 59.6 & 47 & 58.1 & 58 \\
\hline 38 & 014647 & $\begin{array}{l}\text { Chromodomain-helicase-DNA-binding } \\
\text { protein } 2\end{array}$ & CHD2 & 211,344 & - & - & 12 & 1 \\
\hline 39 & P10909 & Clusterin & CLU & 52,495 & 41.4 & 14 & 50.1 & 12 \\
\hline
\end{tabular}


Table 1 A list of 219 identified high-confidence HFF proteins from women underwent successful IVF by LC MALDI TOF/TOF mass spectrometry (FDR < 0.01) (Continued)

\begin{tabular}{|c|c|c|c|c|c|c|c|c|}
\hline 40 & P00740 & Coagulation factor IX & F9 & 51,778 & 15.2 & 1 & - & - \\
\hline 41 & P00742 & Coagulation factor $X$ & F10 & 54,732 & 24.6 & 1 & 14.1 & 1 \\
\hline 42 & P00748 & Coagulation factor XII & $\mathrm{F} 12$ & 67,792 & 29.9 & 4 & 20.8 & 4 \\
\hline 43 & Q5TID7 & Coiled-coil domain-containing protein 181 & CCDC181 & 60,103 & - & - & 7.9 & 1 \\
\hline 44 & P02746 & Complement C1q subcomponent subunit B & C1QB & 26,722 & 20.2 & 1 & 18.6 & 1 \\
\hline 45 & Q9NZP8 & Complement $\mathrm{C} 1 \mathrm{r}$ subcomponent-like protein & C1RL & 53,498 & 8.6 & 1 & 6.2 & 1 \\
\hline 46 & P06681 & Complement C2 & $\mathrm{C} 2$ & 83,268 & 21.5 & 4 & 22.7 & 6 \\
\hline 47 & P01024 & Complement C3 & C3 & 187,148 & 67.1 & 121 & 74.1 & 119 \\
\hline 48 & POCOL4 & Complement C4-A & C4A & 192,785 & 46.6 & 53 & 54.8 & 66 \\
\hline 49 & POCOL5 & Complement C4-B & $\mathrm{C} 4 \mathrm{~B}$ & 192,751 & 46.3 & 52 & 53 & 66 \\
\hline 50 & P01031 & Complement C5 & C5 & 188,305 & 20.3 & 7 & 27.1 & 12 \\
\hline 51 & P13671 & Complement component C6 & C6 & 104,786 & 26 & 6 & 25.5 & 6 \\
\hline 52 & P10643 & Complement component C7 & C7 & 93,518 & 35.2 & 8 & 23.1 & 5 \\
\hline 53 & P07357 & Complement component C8 alpha chain & $\mathrm{C} 8 \mathrm{~A}$ & 65,163 & 24.8 & 5 & 23.5 & 4 \\
\hline 54 & P07358 & Complement component C8 beta chain & $\mathrm{C} 8 \mathrm{~B}$ & 67,047 & 37.1 & 4 & 37.2 & 6 \\
\hline 55 & P07360 & Complement component C8 gamma chain & C8G & 22,277 & 48.5 & 7 & 48 & 5 \\
\hline 56 & P02748 & Complement component C9 & C9 & 63,173 & 36.5 & 8 & 35.8 & 10 \\
\hline 57 & P00751 & Complement factor B & CFB & 85,533 & 41.4 & 20 & 51.4 & 25 \\
\hline 58 & P08603 & Complement factor $\mathrm{H}$ & $\mathrm{CFH}$ & 139,096 & 55.4 & 43 & 56.9 & 45 \\
\hline 59 & Q03591 & Complement factor H-related protein 1 & CFHR1 & 37,651 & 33.9 & 2 & 27.3 & 5 \\
\hline 60 & P05156 & Complement factor I & $\mathrm{CFI}$ & 65,750 & 31.1 & 7 & 31.7 & 5 \\
\hline 61 & P08185 & Corticosteroid-binding globulin & SERPINA6 & 45,141 & 19.5 & 3 & 17.3 & 2 \\
\hline 62 & Q9UBG0 & C-type mannose receptor 2 & MRC2 & 166,674 & 3.2 & 1 & - & - \\
\hline 63 & P01034 & Cystatin-C & CST3 & 15,799 & 22.6 & 1 & - & - \\
\hline 64 & P30876 & $\begin{array}{l}\text { DNA-directed RNA polymerase II subunit } \\
\text { RPB2 }\end{array}$ & POLR2B & 133,897 & - & - & 10.7 & 1 \\
\hline 65 & Q8NHSO & DnaJ homolog subfamily B member 8 & DNAJB8 & 25,686 & 16.8 & 1 & - & - \\
\hline 66 & Q96DT5 & Dynein heavy chain 11, axonemal & DNAH11 & 520,369 & - & - & 9.8 & 1 \\
\hline 67 & Q9C0C9 & E2 ubiquitin-conjugating enzyme & UBE2O & 141,293 & - & - & 3.9 & 1 \\
\hline 68 & O95071 & E3 ubiquitin-protein ligase UBR5 & UBR5 & 309,352 & 7.6 & 1 & - & - \\
\hline 69 & A4FU69 & $\begin{array}{l}\text { EF-hand calcium-binding domain-containing } \\
\text { protein } 5\end{array}$ & EFCAB5 & 173,404 & 8.1 & 1 & - & - \\
\hline 70 & Q16610 & Extracellular matrix protein 1 & ECM1 & 60,674 & 20.7 & 2 & 11.5 & 2 \\
\hline 71 & Q9UGM5 & Fetuin-B & FETUB & 42,055 & 12.8 & 1 & 18.3 & 1 \\
\hline 72 & P02671 & Fibrinogen alpha chain & FGA & 94,973 & 44.8 & 40 & 47.6 & 44 \\
\hline 73 & P02675 & Fibrinogen beta chain & FGB & 55,928 & 72.1 & 53 & 68.6 & 42 \\
\hline 74 & P02679 & Fibrinogen gamma chain & FGG & 51,512 & 69.1 & 36 & 68 & 34 \\
\hline 75 & P02751 & Fibronectin & FN1 & 262,625 & 30.3 & 33 & 31.2 & 34 \\
\hline 76 & Q08380 & Galectin-3-binding protein & LGALS3BP & 65,331 & 22.9 & 1 & 28.7 & 4 \\
\hline 77 & P06396 & Gelsolin & GSN & 85,698 & 43.9 & 16 & 43.6 & 20 \\
\hline 78 & P07093 & Glia-derived nexin & SERPINE2 & 44,002 & 34.7 & 4 & 28.6 & 3 \\
\hline 79 & P22352 & Glutathione peroxidase 3 & GPX3 & 25,552 & 16.4 & 2 & 27 & 1 \\
\hline 80 & Q7Z4J2 & $\begin{array}{l}\text { Glycosyltransferase } 6 \text { domain-containing } \\
\text { protein } 1\end{array}$ & GLT6D1 & 36,274 & 2.6 & 1 & - & - \\
\hline 81 & P0CG08 & Golgi $\mathrm{pH}$ regulator $\mathrm{B}$ & GPR89B & 52,917 & - & - & 7.7 & 1 \\
\hline
\end{tabular}


Table 1 A list of 219 identified high-confidence HFF proteins from women underwent successful IVF by LC MALDI TOF/TOF mass spectrometry (FDR < 0.01) (Continued)

\begin{tabular}{|c|c|c|c|c|c|c|c|c|}
\hline 82 & P00738 & Haptoglobin & $\mathrm{HP}$ & 45,205 & 61.1 & 26 & 58.6 & 23 \\
\hline 83 & P00739 & Haptoglobin-related protein & HPR & 39,030 & 44.3 & 10 & - & - \\
\hline 84 & Q9Y6N9 & Harmonin & USH1C & 62,211 & 7.8 & 1 & - & - \\
\hline 85 & P69905 & Hemoglobin subunit alpha & $\mathrm{HBA} 1 / \mathrm{HBA} 2$ & 15,258 & - & - & 28.2 & 1 \\
\hline 86 & P68871 & Hemoglobin subunit beta & $\mathrm{HBB}$ & 15,998 & 43.5 & 2 & 52.4 & 1 \\
\hline 87 & P02790 & Hemopexin & $\mathrm{HPX}$ & 51,676 & 55.8 & 44 & 76.4 & 50 \\
\hline 88 & P05546 & Heparin cofactor 2 & SERPIND1 & 57,071 & 21 & 6 & 34.9 & 6 \\
\hline 89 & Q04756 & Hepatocyte growth factor activator & HGFAC & 70,682 & 5.3 & 1 & - & - \\
\hline 90 & P04196 & Histidine-rich glycoprotein & HRG & 59,578 & 33 & 15 & 37.9 & 18 \\
\hline 91 & O43365 & Homeobox protein Hox-A3 & HOXA3 & 46,369 & 6.5 & 1 & - & - \\
\hline 92 & P78426 & Homeobox protein Nkx-6.1 & NKX6-1 & 37,849 & 16.4 & 1 & - & - \\
\hline 93 & Q14520 & Hyaluronan-binding protein 2 & $\mathrm{HABP} 2$ & 62,672 & 15.4 & 2 & 11.8 & 3 \\
\hline 94 & P0DOX2 & Immunoglobulin alpha-2 heavy chain & N/A & 48,935 & 39.1 & 14 & 40.9 & 12 \\
\hline 95 & P0DOX3 & Immunoglobulin delta heavy chain & N/A & 56,224 & 19.9 & 1 & 23.4 & 1 \\
\hline 96 & P0DOX4 & Immunoglobulin epsilon heavy chain & N/A & 60,323 & 8.4 & 2 & 15.7 & 2 \\
\hline 97 & P0DOX5 & Immunoglobulin gamma-1 heavy chain & N/A & 49,330 & 70.6 & 144 & 71.9 & 123 \\
\hline 98 & P01876 & Immunoglobulin heavy constant alpha 1 & IGHA1 & 37,655 & 42.8 & 23 & 48.2 & 16 \\
\hline 99 & P01859 & Immunoglobulin heavy constant gamma 2 & IGHG2 & 35,901 & 74.9 & 104 & 69.9 & 92 \\
\hline 100 & P01860 & Immunoglobulin heavy constant gamma 3 & IGHG3 & 41,287 & 72.4 & 69 & 78.3 & 65 \\
\hline 101 & P01861 & Immunoglobulin heavy constant gamma 4 & IGHG4 & 35,941 & 79.8 & 101 & 68.8 & 85 \\
\hline 102 & P01871 & Immunoglobulin heavy constant mu & IGHM & 49,440 & 33.1 & 10 & 34.7 & 12 \\
\hline 103 & $\mathrm{~A} 0 \mathrm{AOC} 4 \mathrm{DH} 31$ & Immunoglobulin heavy variable 1-18 & IGHV1-18 & 12,820 & 53 & 7 & 48.7 & 9 \\
\hline 104 & P23083 & Immunoglobulin heavy variable $1-2$ & IGHV1-2 & 13,085 & 47.9 & 6 & - & - \\
\hline 105 & A0AOC4DH33 & Immunoglobulin heavy variable 1-24 & IGHV1-24 & 12,824 & 38.5 & 2 & 38.5 & 3 \\
\hline 106 & A0A0C4DH29 & Immunoglobulin heavy variable 1-3 & IGHV1-3 & 13,008 & 38.5 & 3 & - & - \\
\hline 107 & A0A0A0MS14 & Immunoglobulin heavy variable 1-45 & IGHV1-45 & 13,508 & 9.4 & 2 & - & - \\
\hline 108 & P01743 & Immunoglobulin heavy variable 1-46 & IGHV1-46 & 12,933 & - & - & 32.5 & 5 \\
\hline 109 & P01742 & Immunoglobulin heavy variable 1-69 & IGHV1-69 & 12,659 & - & - & 34.2 & 5 \\
\hline 110 & P01762 & Immunoglobulin heavy variable 3-11 & IGHV3-11 & 12,909 & 38.5 & 10 & 53.9 & 11 \\
\hline 111 & P01766 & Immunoglobulin heavy variable 3-13 & IGHV3-13 & 12,506 & 60.3 & 6 & - & - \\
\hline 112 & AOA0B4J1VO & Immunoglobulin heavy variable 3-15 & IGHV3-15 & 12,926 & 55.5 & 8 & 42.9 & 7 \\
\hline 113 & P01764 & Immunoglobulin heavy variable 3-23 & IGHV3-23 & 12,582 & 60.7 & 15 & 54.7 & 10 \\
\hline 114 & A0A0B4J1X8 & Immunoglobulin heavy variable 3-43 & IGHV3-43 & 13,077 & - & - & 34.8 & 6 \\
\hline 115 & A0A0A0MS15 & Immunoglobulin heavy variable 3-49 & IGHV3-49 & 13,056 & 47.1 & 3 & 50.4 & 3 \\
\hline 116 & A0A075B6Q5 & Immunoglobulin heavy variable 3-64 & IGHV3-64 & 12,891 & 59.3 & 2 & 18.6 & 1 \\
\hline 117 & $\mathrm{~A} 0 \mathrm{AOC} 4 \mathrm{DH} 42$ & Immunoglobulin heavy variable 3-66 & IGHV3-66 & 12,698 & 61.2 & 14 & 55.2 & 10 \\
\hline 118 & P01780 & Immunoglobulin heavy variable 3-7 & IGHV3-7 & 12,943 & 76.9 & 14 & 77.8 & 12 \\
\hline 119 & A0A0B4J1Y9 & Immunoglobulin heavy variable 3-72 & IGHV3-72 & 13,203 & 55.5 & 9 & - & - \\
\hline 120 & A0A0B4J1V6 & Immunoglobulin heavy variable 3-73 & IGHV3-73 & 12,858 & 58 & 3 & 58 & 4 \\
\hline 121 & P01782 & Immunoglobulin heavy variable 3-9 & IGHV3-9 & 12,945 & 51.7 & 8 & 51.7 & 9 \\
\hline 122 & P06331 & Immunoglobulin heavy variable 4-34 & IGHV4-34 & 13,815 & - & - & 38.2 & 4 \\
\hline 123 & P01824 & Immunoglobulin heavy variable 4-39 & IGHV4-39 & 13,917 & 19.2 & 4 & - & - \\
\hline 124 & $\mathrm{~A} 0 \mathrm{AOC} 4 \mathrm{DH} 38$ & Immunoglobulin heavy variable 5-51 & IGHV5-51 & 12,675 & 66.7 & 9 & 50.4 & 8 \\
\hline 125 & P01834 & Immunoglobulin kappa constant & IGKC & 11,765 & 88.8 & 50 & 92.5 & 37 \\
\hline
\end{tabular}


Table 1 A list of 219 identified high-confidence HFF proteins from women underwent successful IVF by LC MALDI TOF/TOF mass spectrometry (FDR < 0.01) (Continued)

\begin{tabular}{|c|c|c|c|c|c|c|c|c|}
\hline 126 & P0DOX7 & Immunoglobulin kappa light chain & N/A & 23,379 & 61.2 & 52 & 62.6 & 39 \\
\hline 127 & P04430 & Immunoglobulin kappa variable 1-16 & IGKV1-16 & 12,618 & - & - & 34.2 & 2 \\
\hline 128 & A0A075B6S5 & Immunoglobulin kappa variable 1-27 & IGKV1-27 & 12,712 & 47 & 8 & 65 & 8 \\
\hline 129 & P01594 & Immunoglobulin kappa variable 1-33 & IGKV1-33 & 12,848 & 49.6 & 5 & 42.7 & 4 \\
\hline 130 & P01602 & Immunoglobulin kappa variable 1-5 & IGKV1-5 & 12,782 & 30.8 & 3 & 30.8 & 6 \\
\hline 131 & AOAOC4DH72 & Immunoglobulin kappa variable 1-6 & IGKV1-6 & 12,697 & 47 & 4 & 47 & 5 \\
\hline 132 & A0A0C4DH69 & Immunoglobulin kappa variable 1-9 & IGKV1-9 & 12,715 & 74.4 & 5 & 44.4 & 5 \\
\hline 133 & P01611 & Immunoglobulin kappa variable 1D-12 & IGKV1D-12 & 12,620 & 44.4 & 5 & 49.6 & 7 \\
\hline 134 & A0A0B4J2D9 & Immunoglobulin kappa variable 1D-13 & IGKV1D-13 & 12,569 & 13.7 & 1 & - & - \\
\hline 135 & A0A075B6S4 & Immunoglobulin kappa variable 1D-17 & IGKV1D-17 & 12,835 & 28.2 & 1 & 43.6 & 2 \\
\hline 136 & P04432 & Immunoglobulin kappa variable 1D-39 & IGKV1D-39 & 12,737 & 47 & 6 & 47.9 & 6 \\
\hline 137 & P06310 & Immunoglobulin kappa variable 2-30 & IGKV2-30 & 13,185 & 50 & 5 & 63.3 & 7 \\
\hline 138 & P01615 & Immunoglobulin kappa variable 2D-28 & IGKV2D-28 & 12,957 & 33.3 & 5 & 40.8 & 5 \\
\hline 139 & A0A075B6S2 & Immunoglobulin kappa variable 2D-29 & IGKV2D-29 & 13,143 & - & - & 20.8 & 5 \\
\hline 140 & P01614 & Immunoglobulin kappa variable 2D-40 & IGKV2D-40 & 13,310 & 37.2 & 6 & 37.2 & 5 \\
\hline 141 & P04433 & Immunoglobulin kappa variable 3-11 & IGKV3-11 & 12,575 & 54.8 & 16 & 49.6 & 10 \\
\hline 142 & P01624 & Immunoglobulin kappa variable 3-15 & IGKV3-15 & 12,496 & 42.6 & 9 & 50.4 & 8 \\
\hline 143 & P01619 & Immunoglobulin kappa variable 3-20 & IGKV3-20 & 12,557 & 70.7 & 16 & 70.7 & 14 \\
\hline 144 & A0A087WSY6 & Immunoglobulin kappa variable 3D-15 & IGKV3D-15 & 12,534 & 42.6 & 10 & 56.5 & 8 \\
\hline 145 & $\mathrm{~A} 0 \mathrm{AOC} 4 \mathrm{DH} 25$ & Immunoglobulin kappa variable 3D-20 & IGKV3D-20 & 12,515 & 64.7 & 10 & 64.7 & 8 \\
\hline 146 & P06312 & Immunoglobulin kappa variable 4-1 & IGKV4-1 & 13,380 & 34.7 & 10 & 40.5 & 6 \\
\hline 147 & A0M8Q6 & Immunoglobulin lambda constant 7 & IGLC7 & 11,254 & 54.7 & 13 & 53.8 & 10 \\
\hline 148 & AOAOB4J1U3 & Immunoglobulin lambda variable 1-36 & IGLV1-36 & 12,478 & 13.7 & 1 & 13.7 & 1 \\
\hline 149 & P01703 & Immunoglobulin lambda variable 1-40 & IGLV1-40 & 12,302 & 21.2 & 2 & - & - \\
\hline 150 & P01700 & Immunoglobulin lambda variable 1-47 & IGLV1-47 & 12,284 & 54.7 & 4 & 39.3 & 3 \\
\hline 151 & P01706 & Immunoglobulin lambda variable 2-11 & IGLV2-11 & 12,644 & 22.7 & 3 & - & - \\
\hline 152 & A0A075B6K4 & Immunoglobulin lambda variable 3-10 & IGLV3-10 & 12,441 & 40 & 4 & 40 & 3 \\
\hline 153 & P01714 & Immunoglobulin lambda variable 3-19 & IGLV3-19 & 12,042 & 50 & 2 & 42.9 & 1 \\
\hline 154 & P80748 & Immunoglobulin lambda variable 3-21 & IGLV3-21 & 12,446 & 35.9 & 3 & - & - \\
\hline 155 & P01717 & Immunoglobulin lambda variable 3-25 & IGLV3-25 & 12,011 & - & - & 43.8 & 3 \\
\hline 156 & P01721 & Immunoglobulin lambda variable 6-57 & IGLV6-57 & 12,566 & 20.5 & 2 & - & - \\
\hline 157 & PODOX8 & Immunoglobulin lambda-1 light chain & N/A & 22,830 & 44.4 & 23 & 44.4 & 20 \\
\hline 158 & P15814 & Immunoglobulin lambda-like polypeptide 1 & IGLL1 & 22,963 & 23 & 5 & 23 & 5 \\
\hline 159 & P35858 & $\begin{array}{l}\text { Insulin-like growth factor-binding protein } \\
\text { complex acid labile subunit }\end{array}$ & IGFALS & 66,035 & 23.1 & 4 & 27.4 & 6 \\
\hline 160 & P16144 & Integrin beta-4 & ITGB4 & 202,167 & 4.9 & 1 & - & - \\
\hline 161 & P19827 & Inter-alpha-trypsin inhibitor heavy chain $\mathrm{H} 1$ & $\mathrm{ITIH} 1$ & 101,389 & 33.6 & 20 & 33.7 & 25 \\
\hline 162 & P19823 & Inter-alpha-trypsin inhibitor heavy chain $\mathrm{H} 2$ & $\mathrm{ITIH} 2$ & 106,463 & 35.9 & 18 & 42.6 & 20 \\
\hline 163 & Q06033 & Inter-alpha-trypsin inhibitor heavy chain H3 & ITIH3 & 99,849 & 5.2 & 1 & 15.5 & 1 \\
\hline 164 & Q14624 & Inter-alpha-trypsin inhibitor heavy chain $\mathrm{H} 4$ & ITIH4 & 103,357 & 38.4 & 23 & 47 & 26 \\
\hline 165 & Q15811 & Intersectin-1 & ITSN1 & 195,422 & - & - & 9.9 & 1 \\
\hline 166 & P29622 & Kallistatin & SERPINA4 & 48,542 & 26.5 & 4 & 23 & 5 \\
\hline 167 & Q92764 & Keratin, type I cuticular Ha5 & KRT35 & 50,361 & - & - & 16.7 & 1 \\
\hline 168 & P13645 & Keratin, type I cytoskeletal 10 & KRT10 & 58,827 & 5.8 & 1 & - & - \\
\hline
\end{tabular}


Table 1 A list of 219 identified high-confidence HFF proteins from women underwent successful IVF by LC MALDI TOF/TOF mass spectrometry (FDR < 0.01) (Continued)

\begin{tabular}{|c|c|c|c|c|c|c|c|c|}
\hline 169 & P04264 & Keratin, type II cytoskeletal 1 & KRT1 & 66,039 & 23.6 & 3 & 30 & 2 \\
\hline 170 & P01042 & Kininogen-1 & KNG1 & 71,957 & 53.7 & 25 & 41 & 23 \\
\hline 171 & P02750 & Leucine-rich alpha-2-glycoprotein & LRG1 & 38,178 & 21.6 & 4 & 27.1 & 5 \\
\hline 172 & P18428 & Lipopolysaccharide-binding protein & LBP & 53,384 & 14.8 & 1 & 13.3 & 1 \\
\hline 173 & P51884 & Lumican & LUM & 38,429 & 30.2 & 3 & 27.8 & 3 \\
\hline 174 & P14174 & Macrophage migration inhibitory factor & MIF & 12,476 & 18.3 & 2 & - & - \\
\hline 175 & P01033 & Metalloproteinase inhibitor 1 & TIMP1 & 23,171 & 18.8 & 2 & 34.8 & 2 \\
\hline 176 & Q7Z5P9 & Mucin-19 & MUC19 & 805,253 & 4.3 & 1 & - & - \\
\hline 177 & P35579 & Myosin-9 & MYH9 & 226,532 & - & - & 15.8 & 1 \\
\hline 178 & Q96PD5 & $\mathrm{N}$-acetylmuramoyl-L-alanine amidase & PGLYRP2 & 62,217 & 26 & 7 & 29.3 & 6 \\
\hline 179 & A6NHNO & Otolin-1 & OTOL1 & 49,422 & 15.3 & 1 & - & - \\
\hline 180 & P04180 & Phosphatidylcholine-sterol acyltransferase & LCAT & 49,578 & 15.5 & 2 & - & - \\
\hline 181 & P36955 & Pigment epithelium-derived factor & SERPINF1 & 46,312 & 22.3 & 5 & 17.9 & 5 \\
\hline 182 & P03952 & Plasma kallikrein & KLKB1 & 71,370 & 23 & 6 & 26.5 & 6 \\
\hline 183 & P05155 & Plasma protease $\mathrm{C} 1$ inhibitor & SERPING1 & 55,154 & 34.8 & 9 & 33.2 & 16 \\
\hline 184 & P05154 & Plasma serine protease inhibitor & SERPINA5 & 45,675 & 13.6 & 3 & - & - \\
\hline 185 & P00747 & Plasminogen & PLG & 90,569 & 63 & 30 & 58.8 & 32 \\
\hline 186 & Q96GD3 & Polycomb protein SCMH1 & SCMH1 & 73,354 & 4.7 & 1 & - & - \\
\hline 187 & Q8WUM4 & Programmed cell death 6-interacting protein & PDCD6IP & 96,023 & - & - & 14.1 & 1 \\
\hline 188 & P46013 & Proliferation marker protein Ki-67 & MKI67 & 358,694 & 11.9 & 1 & 21.8 & 1 \\
\hline 189 & P15309 & Prostatic acid phosphatase & ACPP & 44,566 & 25.1 & 4 & 17.9 & 2 \\
\hline 190 & P02760 & Protein AMBP & $\mathrm{AMBP}$ & 38,999 & 38.9 & 11 & 42.1 & 12 \\
\hline 191 & Q9UK55 & Protein Z-dependent protease inhibitor & SERPINA10 & 50,707 & 15.5 & 2 & 18.9 & 2 \\
\hline 192 & Q96PF1 & $\begin{array}{l}\text { Protein-glutamine gamma- } \\
\text { glutamyltransferase Z }\end{array}$ & TGM7 & 79,941 & - & - & 7.5 & 1 \\
\hline 193 & P00734 & Prothrombin & F2 & 70,037 & 59.8 & 33 & 62.4 & 31 \\
\hline 194 & P02753 & Retinol-binding protein 4 & RBP4 & 23,010 & 40.3 & 11 & 55.7 & 13 \\
\hline 195 & O94885 & SAM and SH3 domain-containing protein 1 & SASH1 & 136,653 & - & - & 10.3 & 1 \\
\hline 196 & P04279 & Semenogelin-1 & SEMG1 & 52,131 & 30.5 & 5 & 32.3 & 5 \\
\hline 197 & Q02383 & Semenogelin-2 & SEMG2 & 65,444 & 21 & 3 & 18 & 5 \\
\hline 198 & P57059 & Serine/threonine-protein kinase SIK1 & SIK1 & 84,902 & - & - & 7.3 & 1 \\
\hline 199 & P02787 & Serotransferrin & TF & 77,064 & 71.4 & 143 & 79.4 & 185 \\
\hline 200 & P02768 & Serum albumin & $A L B$ & 69,367 & 89.3 & 607 & 91.3 & 550 \\
\hline 201 & P35542 & Serum amyloid A-4 protein & SAA4 & 14,747 & 30 & 2 & 49.2 & 6 \\
\hline 202 & P02743 & Serum amyloid P-component & APCS & 25,387 & 26.5 & 5 & 25.1 & 5 \\
\hline 203 & P27169 & Serum paraoxonase/arylesterase 1 & PON1 & 39,731 & 24.5 & 7 & 19.2 & 5 \\
\hline 204 & P04278 & Sex hormone-binding globulin & SHBG & 43,779 & 18.7 & 4 & 21.9 & 3 \\
\hline 205 & P09486 & SPARC & SPARC & 34,632 & - & - & 5.3 & 1 \\
\hline 206 & Q6N022 & Teneurin-4 & TENM4 & 307,957 & 5.3 & 1 & - & - \\
\hline 207 & P05452 & Tetranectin & CLEC3B & 22,537 & 22.8 & 2 & 30.2 & 2 \\
\hline 208 & P05543 & Thyroxine-binding globulin & SERPINA7 & 46,325 & 14.5 & 1 & 23.6 & 2 \\
\hline 209 & Q8WZ42 & Titin & TTN & $3,816,030$ & 10.6 & 1 & - & - \\
\hline 210 & P21675 & Transcription initiation factor TFIID subunit 1 & TAF1 & 212,677 & - & - & 7 & 1 \\
\hline 211 & Q66K66 & Transmembrane protein 198 & TMEM198 & 39,475 & 2.5 & 2 & 2.5 & 1 \\
\hline
\end{tabular}


Table 1 A list of 219 identified high-confidence HFF proteins from women underwent successful IVF by LC MALDI TOF/TOF mass spectrometry (FDR < 0.01) (Continued)

\begin{tabular}{lllllllll}
\hline 212 & P02766 & Transthyretin & TTR & 15,887 & 69.4 & 12 & 69.4 & 19 \\
213 & P13611 & Versican core protein & VCAN & 372,820 & - & - & 5.2 & 2 \\
214 & P02774 & Vitamin D-binding protein & GC & 52,964 & 63.9 & 29 & 60.3 & 28 \\
215 & P04070 & Vitamin K-dependent protein C & PROC & 52,071 & - & - & 2.2 & 1 \\
216 & P07225 & Vitamin K-dependent protein S & PROS1 & 75,123 & 12.6 & 2 & - & - \\
217 & P04004 & Vitronectin & VTN & 54,306 & 32.6 & 11 & 32.2 & 15 \\
218 & Q6PF04 & Zinc finger protein 613 & ZNF613 & 70,143 & 6.6 & 1 & - & - \\
219 & P25311 & Zinc-alpha-2-glycoprotein & AZGP1 & 34,259 & 52.7 & 14 & 52 & 17 \\
\hline
\end{tabular}

$1 \mathrm{~min}$; 90\% B, $8.5 \mathrm{~min}$; 90-5\% B, $0.5 \mathrm{~min}$; 5\% B, $10 \mathrm{~min}$. The tryptic peptides were separated at an eluent flow rate of $0.8 \mathrm{ml} / \mathrm{min}$ and monitored at $214 \mathrm{~nm}$. Totally, 28 eluent fractions were collected and dried by a SPD2010 SpeedVac concentrator system (Thermo, USA).

\section{Second dimension low pH RP chromatography coupled with MS/MS measurement}

According to the previous method [22], the samples were dried under vacuum and reconstituted in $30 \mu \mathrm{l}$ of $0.1 \%(v / v)$ formic acid, $2 \%(v / v)$ acetonitrile in water for subsequent analyses. Each fraction was separated and spotted using the Tempo ${ }^{\mathrm{rm}}$ LC-MALDI Spotting System (AB SCIEX, USA). Peptides were separated by a C18 AQ $150 \times 0.2 \mathrm{~mm}$ column ( $3 \mu \mathrm{m}$, Michrom, USA) using a linear gradient formed by buffer A ( $2 \%$ acetonitrile, $0.1 \%$ formic acid) and buffer B (98\% acetonitrile, 0.1\% formic acid), from $5 \%$ to $35 \%$ of buffer B over 90 min at a flow rate of $0.5 \mu \mathrm{L} / \mathrm{min}$. The eluted peptides were mixed with matrix solution $(5 \mathrm{mg} / \mathrm{mL}$ in $70 \%$ acetonitrile, $0.1 \%$ trifluoroacetic acid) at a flow rate of $2 \mu \mathrm{L} / \mathrm{min}$ pushed by additional syringe pump. For each fraction, 616 spots were spotted on a $123 \times 81 \mathrm{~mm}$ LC-MALDI plate insert. Then the spots were analyzed using MALDITOF/TOF 5800 mass spectrometer (AB SCIEX, USA). A full-scan MS experiment $(\mathrm{m} / \mathrm{z}$ range from 800 to 4000) was acquired, and then the top 40 ions were detected by MS/MS.

\section{Protein identification}

Protein identification was performed with the ProteinPi$\operatorname{lot}^{\mathrm{Tm}}$ software (version 4.0.1; AB SCIEX). Each MS/MS spectrum was searched against a database (2017_03 released UniProtKB/Swiss-Prot human database, 20,183 entries) and a decoy database for FDR analysis (programmed in the software). The search parameters were as follows: trypsin enzyme; maximum allowed missed cleavages 1; Carbamidomethyl cysteine; biological modifications programmed in the algorithm. Proteins with high-confidence $($ FDR $<0.01)$ were considered as positively identified proteins.

\section{Bioinformatics}

The gene ontology enrichment analysis of HFF proteins were performed by using online bioinformatics tools of PANTHER (Protein ANalysis THrough Evolutionary Relationships) classification system (released 11.1, 2016-1024) (http://pantherdb.org/) [23] and DAVID (The Database for Annotation, Visualization and Integrated Discovery) bioinformatics resources 6.8 (https://david.ncifcrf.gov/) [24]. Each protein was placed in only one category, and those with no annotation and supporting information were categorized as "Unknown". The pathway map of HFF proteins were achieved through KEGG: Kyoto Encyclopedia of Genes and Genomes (Release 81.0, 201701-01) (http://www.kegg.jp) [25]. The protein-protein interaction network for the HFF proteins was annotated using the STRING (search tool for recurring instances of neighbouring genes) database (released 10.0, 2016-04-16) (http:// string-db.org/) [26]. The venn diagram was drawn through a online software "Calculate and draw custom Venn diagrams" (http://bioinformatics.psb.ugent.be/webtools/Venn/).

\section{Western blot analysis}

According to the method described previously [27, 28], $50 \mu \mathrm{g}$ HFF protein were separated by a $12 \%$ SDS-PAGE gel and then electronically transferred onto a nitrocellulose membrane. The resultant membrane was blocked with $5 \%(w / v)$ skimmed milk for $1 \mathrm{~h}$ at $37{ }^{\circ} \mathrm{C}$, and then was incubated with the primary antibody (Abcam, Cambridge, USA, diluted 1:2000) at $4{ }^{\circ} \mathrm{C}$ overnight. After washing with TBST for three times, the membranes were incubated with horse-radish peroxidase-conjugated secondary antibody (diluted 1:5000, Zhong-Shan Biotechnology, Beijing, China) at room temperature for $1 \mathrm{~h}$. The immunoreactive proteins was visualized by enhanced chemiluminescence detection reagents (Pierce, Rockford, IL, USA) (Additional file 1: Table S1).

\section{Results}

Identification of high-confidence HFF proteome by dual RP-HPLC coupled with MALDI TOF/TOF mass spectrometry. 
A peptide sequencing strategy was applied by using two-dimensional chromatography-MALDI TOF/TOF mass spectrometry. We employed high $\mathrm{pH}(\mathrm{pH} 10)$ reverse phase liquid chromatography to decrease the complexity of the tryptic digest of the HFF proteins, and collected 28 fractions. Then each fraction was further separated by low $\mathrm{pH}(\mathrm{pH} 3)$ reverse phase liquid chromatography, and spotted on the plate using the Tempo $^{\text {tw }}$ LC-MALDI Spotting System. After sequencing by a 5800 MALDI TOF/TOF mass spectrometry, the resultant spectra were analyzed by ProteinPilot ${ }^{\mathrm{Tm}}$ soft- $^{-}$ ware by searching the reviewed Swiss-Prot human database (20,183 sequences, 2017_03 released). A total of 219 unique high-confidence $(\mathrm{FDR}<0.01)$ proteins were identified by two replicates (Table 1). Experiment 1 and 2 identified 188 with 2747 unique peptides and 179 proteins with 2800 unique peptides, respectively. 148 common proteins were shared between the two experiments. Figure 1 showed representative MS/MS spectra of peptides from the identified HFF proteins. The $\mathrm{m} / \mathrm{z}$ of precursor (Fig. 2c) was over 2500, and almost all bions and y-ions were still obtained based on a 5800 MALDI TOF/TOF mass spectrometry.

\section{Bioinformatics analysis of the HFF proteome}

The proteins identified by mass spectrometry were broadly placed into several GO categories on the basis of the PANTHER, DAVID and PubMed databases (Fig. 2). Based on molecular function, the majority (31\%) of proteins were related to immunity, whereas other involved protein functions were mainly complement and coagulation (17\%), protease or inhibitor (14\%), and transportation (10\%) (Fig. 2a). Based on subcellular localization, the majority $(64 \%)$ of the identified proteins located in extracellular region. Other main locations were extracellular matix (7\%), nuleus (6\%), and cytoskeleton (5\%) (Fig. 2b). Based on biological process, the majority (28\%) of proteins was related to developmental process, and the next prevalence was immunological system process (26\%). The other groups were involved into protein metabolic process (12\%), reproduction (5\%), lipid metabolic process (3\%), and transportation (2\%) (Fig. 2c).

KEGG pathway analysis was performed to map HFF protein interactions, Pathways associated with complement and coagulation cascades ( $\mathrm{P}_{-}$Value $=5.8 \mathrm{E}-52$ ), vitamin digestion and absorption ( $\mathrm{P}_{-}$Value $=0.023$ ), and $\left(P_{-}\right.$Value $\left.=0.066\right)$ were significantly enriched. Figure 3

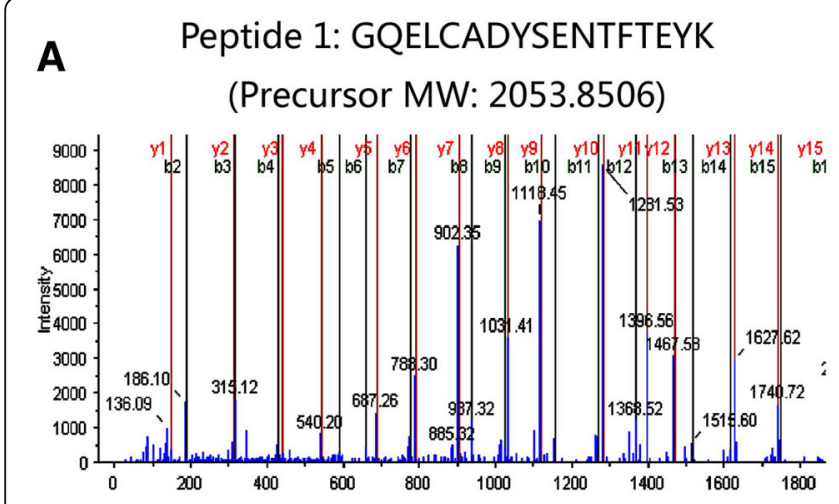

C

Peptide 1: GNDDHWIVDTDYDTYAVQYSCR

(Precursor MW: 2692.0667)

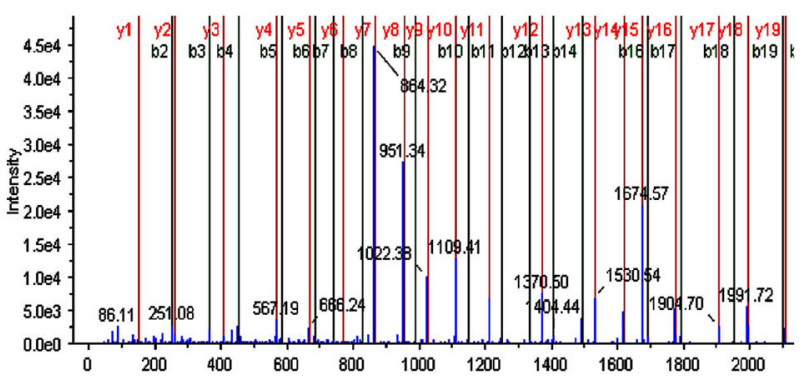

D

Peptide 2: YWGVASFLQK

(Precursor MW: 1197.6047)

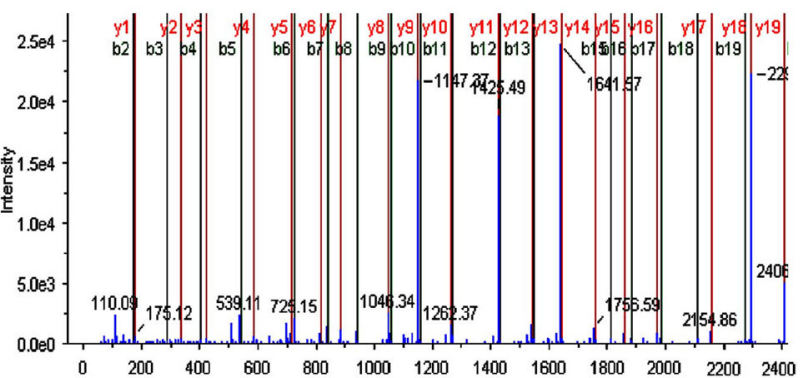

Fig. 1 Identification of HFF proteins by LC MALDI TOF/TOF MS Spectra. The MS/MS map (a, b) marked with b ions and y ions for vitamin Dbinding protein identification. The sequences of precursor at m/z 2053.8506 and 2353.9646 were analyzed by MS/MS to be GQELCADYSENTFTEYK and SYLSMVGSCCTSASPTVCFLK and the protein identified as vitamin D-binding protein. The MS/MS map (c, d) marked with b ions and y ions for retinol-binding protein 4 identification. The sequences of precursor at m/z 2692.0667 and 1197.6047 were analyzed by MS/MS to be GNDDHWIVDTDYDTYAVQYSCR and YWGVASFLQK and the protein identified as retinol-binding protein 4 


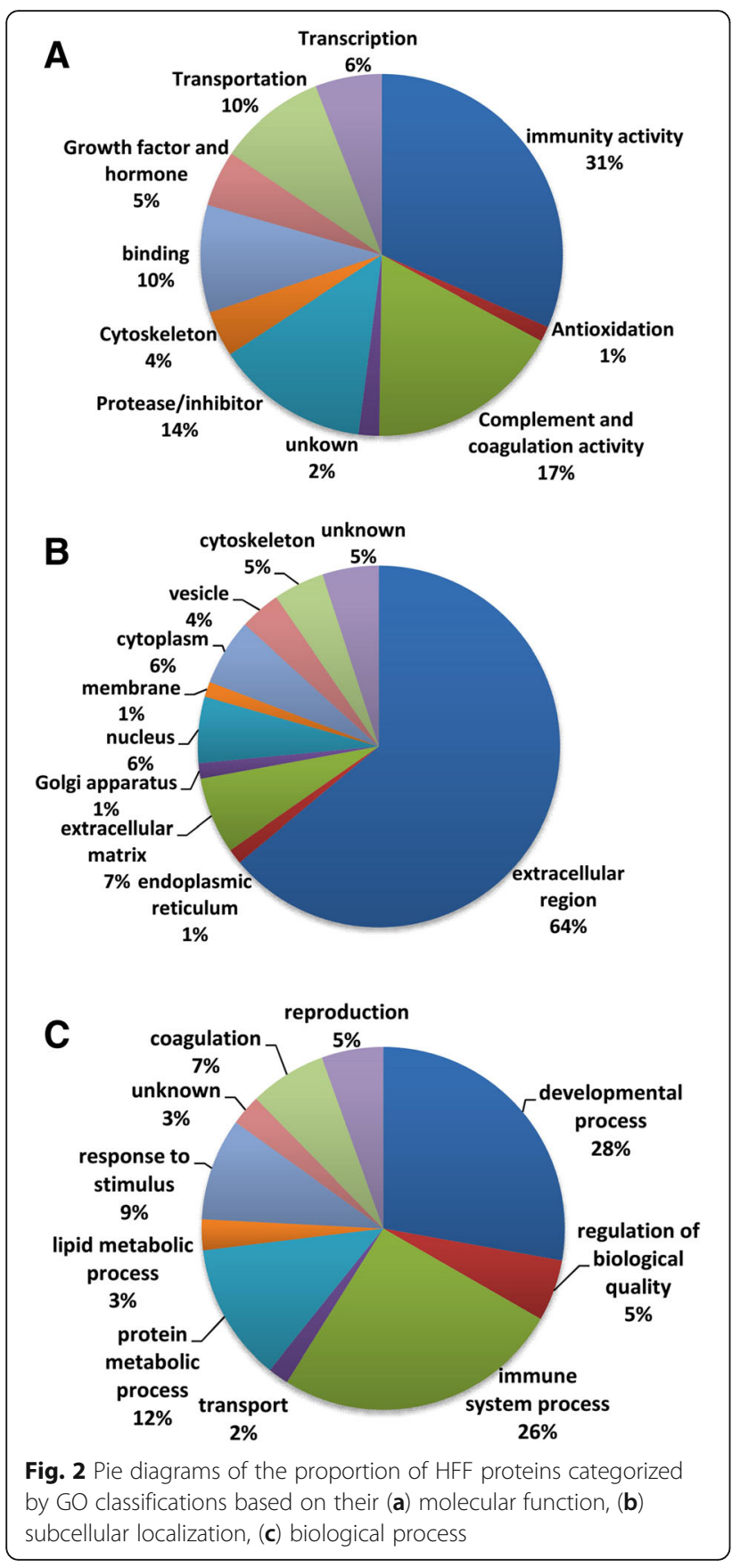

showed the complement and coagulation cascades pathway which included 17 (7.8\%) and 21 (9.6\%) highlighted HFF proteins in coagulation cascade and complement cascade, respectively.

A protein-protein interaction network was constructed by retrieving the STRING database. 151 proteins were in connection with other proteins, which lead to 738 paired relationships. As an example, 21 of 151 proteins related to basement membrane-specific heparan sulfate proteoglycan core protein (HSPG) was chosen, and 105 paired relationships were connected (Fig. 4).

\section{Comparison of present HFF proteome, the previous} reported HFF proteome and human plasma proteome To disclose the overlap of the HFF proteomes between different labs and to explore the orign of the HFF proteins, the previous reported HFF proteins [14] and the human plasma proteome [29] were selected, whose protein identification criteria were both at a false discovery rate (FDR) of $1 \%$. The results reflected the overlap of our HFF proteins and the previously reported HFF proteins with human plasma proteins (Fig. 5). A total of $49 \%$ proteins in our HFF data were common to the previous HFF data. Compared with human plasma proteins, $69 \%$ proteins from our HFF data and $64 \%$ proteins from previous HFF data were common to human plasma proteins.

\section{Western blotting analysis}

To verify the confidence of the proteome data, the expression patterns of 3 HFF proteins (retinol-binding protein 4 , vitamin D-binding protein and lactotransferrin) from 10 women undergoing successful IVF were analyzed by western blotting (Fig. 6). Those three proteins could be detected in all 10 HFF samples. Compared with retinol-binding protein 4 and lactotransferrin, the expression of vitamin D-binding protein was relatively constant level in the HFF of ten women.

\section{Discussion}

Proteomics has been carried out to discover HFF biomarkers for decades, and liquid chromatography coupled with ion trap MS became widely available with the development of high-throughput sequencing. The identification of HFF proteins from women with and without endometriosis was performed using ESI MS/MS [30]. Nanoflow LC-MS/MS combined with TMT labeling was used to identify HFF biomarkers from women undergoing IVF/ICSI treatment with or without folic acid supplement [31]. Another advance LTQ Orbitrap system coupled with LC was also applied to comparing HFF proteins between fertilized oocytes and non-fertilized oocytes from the same patient [32]. Based on sample pre-fractionation using microscale in-solution isoelectric focusing (IEF), capillary electrophoresis (CE) coupled offline to matrix assisted laser desorption/ionization time of flight tandem mass spectrometry (MALDI TOF MS/MS) identified 73 unique proteins [33]. Hanrieder and coworkers [34] utilized a proteomic strategy of IEF and reversed-phase nano-liquid chromatography coupled to MALDI TOF/TOF mass spectrometry to identify 69 proteins related to controlled ovarian hyper stimulation $(\mathrm{COH})$ during IVF. However, limited proteins were identified which delayed the research of HFF protein networks.

In the present work, a dual RP-HPLC coupled with MALDI TOF/TOF mass spectrometry was performed to identify HFF protein profiles associated with successful 


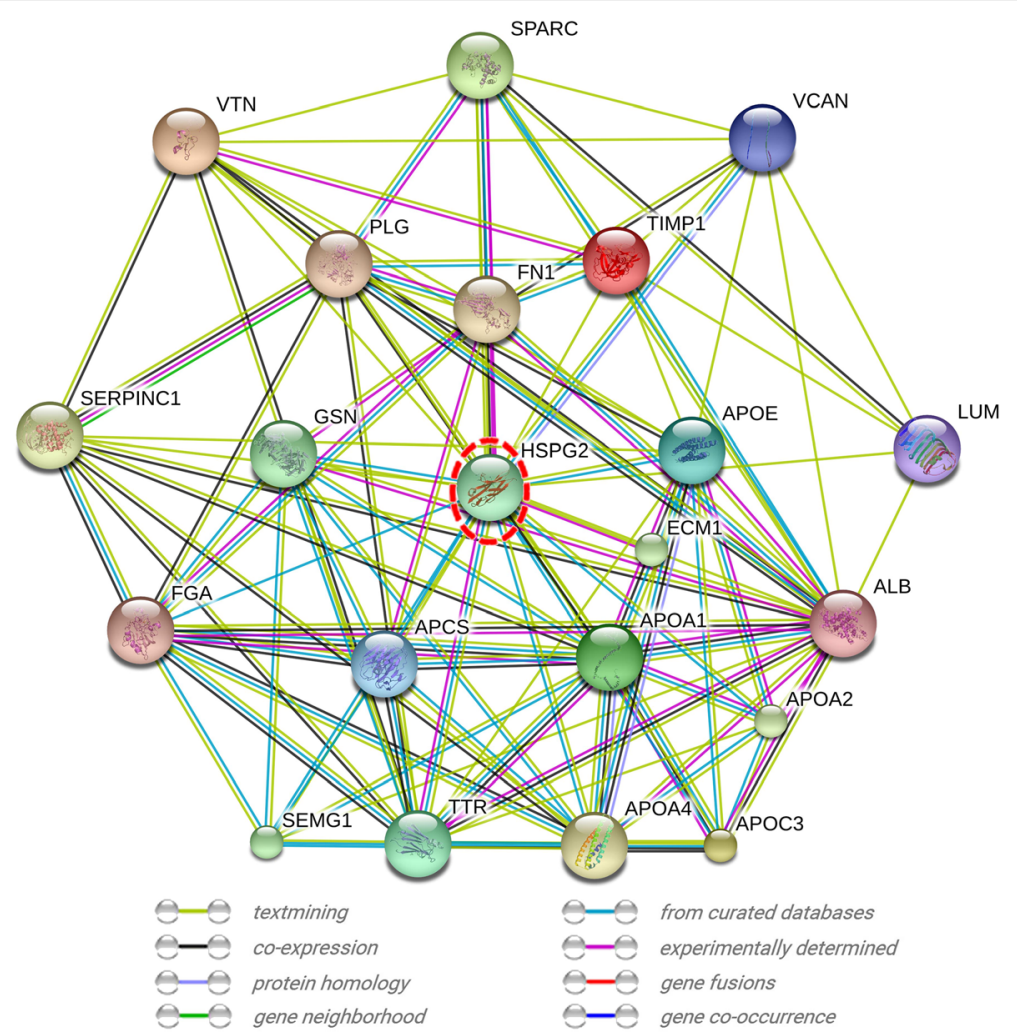

Fig. 3 Presentative Network of protein HSPG2 in the identified HFF proteome. A total of 21 genes are connected with 105 paired relationships annotated by STRING database. The relationships among proteins were derived from evidence that includes textmining, co-expression, protein homology, gene neighborhood, from curated databases, experimentally determined, gene fusions, and gene co-occurrence (as shown in the legend with different color)

IVF, and 219 unique high-confidence (FDR < 0.01) HFF proteins were identified by searching the reviewed Swiss-Prot human database (20,183 sequences). Meanwhile, the new strategy indicated that the effective dual reverse LC pre-fractionation [21] could identify more HFF proteins.

Ambekar and co-workers carried out SDS-PAGE, OFFGEL and SCX-based separation followed by LCMS/MS (an LTQ-Orbitrap Velos MS) to identify 480 HFF proteins with high confidence (FDR < 0.01) [14]. A comparison with our results and these data showed that more than $50 \%$ proteins in present study were not found in previous dataset (Additional file 2: Figure S1), which indicated that the data from different MS platforms were complementary. Retinol-binding protein 4 and vitamin D-binding protein were verified by western blotting, and the results showed they were all expressed in the 10 HFF samples. Lactotransferrin was uniquely included in Ambekar's data, and was also successfully detected by western blotting in our study. This result not only testified the good quality of Ambekar's data, but also facilitated to integrate the data from different MS platform in the future. Interestingly, more than $60 \%$ of combined
HFF proteins from our data and Ambekar's data were found in the reported human plasma data [29]. HFF was a complex mixture, and the content of HFF mainly originates from the transfer of blood plasma constituents via theca capillaries, and the secretion of granulosa and thecal cells [5]. From the above contrast, we considered the transfer of plasma proteins was the major source of HFF, and the alternative permeability of theca capillaries would change the HFF compositions which inevitably impaired the oocyte quality, and even caused unsuccessful IVF outcome.

Bioinformatics analysis showed that 5\% HFF proteins were involved in lipid metabolism and transport process. It has been reported that ageing could decrease apolipoprotein A1 and apolipoprotein CII, while increase apolipoprotein $\mathrm{E}$, which were associated with the decline in production of mature oocytes and the decline in fertility potential [35]. Preconception folic acid supplementation upregulated apolipoprotein A-I and apolipoprotein C-I of the HDL pathway in human follicular fluid, which increased embryo quality and IVF/ICSI treatment outcome [30]. In our HFF data, apolipoprotein A-I, apolipoprotein A-II, apolipoprotein A-IV, apolipoprotein C-I, 


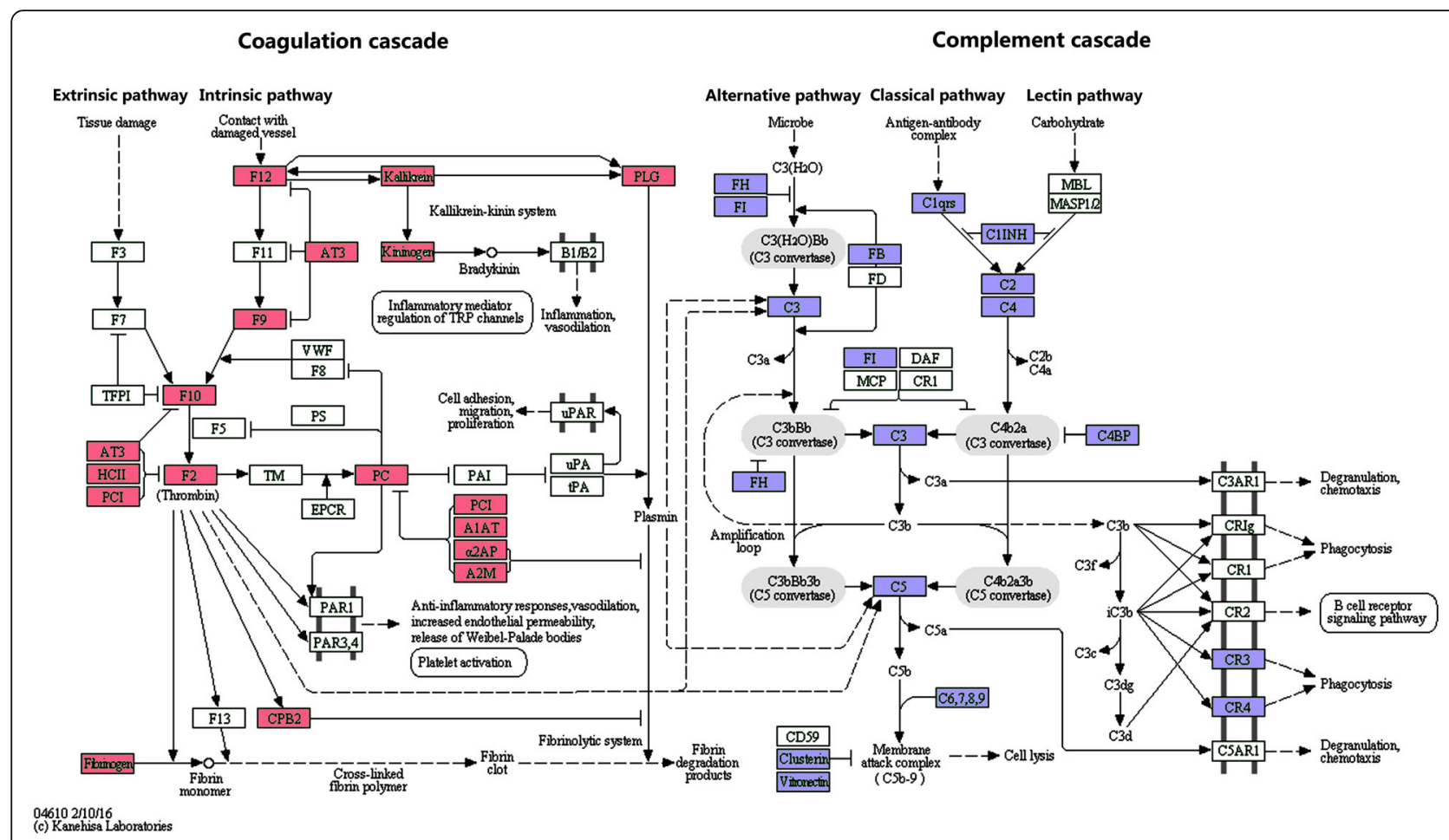

Fig. 4 The KEGG pathway of complement and coagulation cascades with the identified HFF proteins highlighted. Generated by the KEGG online (hsa04610), this diagram showed the roles if HFF proteins in complement (Red) and coagulation cascades (Blue)

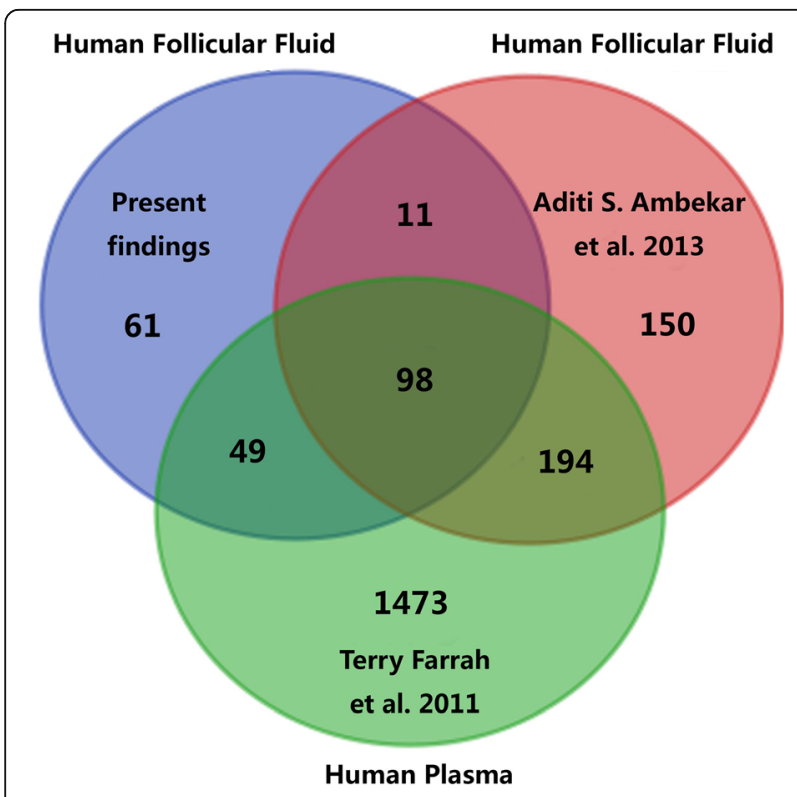

Fig. 5 Venn diagram of the overlap of HFF and human plasma protein datasets. Distribution of our present findings or the previously reported HFF proteins (Aditi S. Ambekar et al. 2013) and their overlap with those reported in human plasma (Terry Farrah et al. 2011) apolipoprotein C-II, apolipoprotein C-III, apolipoprotein $\mathrm{D}$, apolipoprotein $\mathrm{E}$, apolipoprotein $\mathrm{F}$, and apolipoprotein $\mathrm{M}$ were all found, which indicated that those apolipoproteins were related to cholesterol homeostasis and steroidogenesis and played important roles in the maintenance of oocyte maturation microenvironment.

Pathway analysis showed that complement and coagulation cascades were the most prominent pathways $\left(\mathrm{P}_{-}\right.$Value $\left.=5.8 \mathrm{E}-52\right)$. Complement cascade promoted coagulation through the inhibition of fibrinolysis, and coagulation cascade in return amplified complement activation. Complement cross_talked with coagulation in a reciprocal way [36]. For example, plasmin, thrombin, elastase and plasma kallikrein could activate C3 [37]. Coagulation activation factor XII could cleave C1 to activate the classical complement pathway [38]. And thrombin could also directly cleave $\mathrm{C} 5$ to generate active C5a [39]. Among our HFF proteins, components (F12, KLKB1, PLG, KNG1, F9, F10, SERPINC1, SERPIND1, SERPINA5, F2, PROS1, PROC, SERPINA1, SERPINF2, $\mathrm{A} 2 \mathrm{M}, \mathrm{CPB} 2$, and FGA) of extrinsic pathway and intrinsic pathway in coagulation cascade and those $(\mathrm{FH}, \mathrm{FI}, \mathrm{FB}$, C3, C1qrs, SERPING1, C2, C4, C4BP, C5, C6, C7, C8A, C8B, C8G, C9, FGA, FGG, PLG, FGB, F10) of alternative pathway, classical pathway, and lectin pathway in complement cascade were all identified. During follicle development and ovulation, coagulation system in HFF 


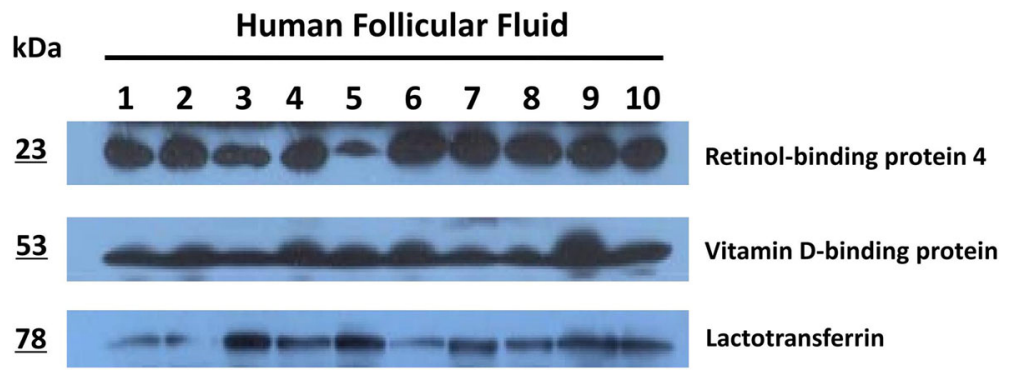

Fig. 6 Immunoblot analysis of retinol-binding protein 4, vitamin D-binding protein and lactotransferrin in 10 HFF samples of women underwent successful IVF. Protein lysates prepared from $10 \mathrm{HFF}$ samples were examined by immunoblots using specific antibodies recognizing the retinolbinding protein $4(23 \mathrm{kDa})$, vitamin D-binding protein $(53 \mathrm{kDa})$ and lactotransferrin $(78 \mathrm{kDa})$

contributed to HFF liquefaction, fibrinolysis and the breakdown of follicle wall [40, 41]. Follicle development had been hypothesized as the controlled inflammatory processes in 1994 [42], and inappropriate complement activation was linked to abortion [43]. Inhibition of complement activation improved angiogenesis failure and rescued pregnancies [44]. The paired comparison of HFF with plasma showed C3, C4, C4a, and C9 as well as complement factor $\mathrm{H}$ and clusterin might contribute to the inhibition of complement cascade activity for women undergoing controlled ovarian stimulation for IVF [45]. However there were still debates on the role of complement cascade in IVF. Physiologic complement activation protected the host against infection in normal pregnancy [46]. In comparison with those non-fertilized oocytes, C3 was more abundant in HFF from fertilized oocytes [47]. In the course of IVF treatment, the functions of complement and coagulation cascade were very complicated during ovarian hyperstimulation. More works were still deserved in both mechanism research and clinical practice.

Based on the analysis of STRING, we discovered a profound HFF protein-protein interaction networks. 151 of 219 HFF proteins participated in the network with 738 paired relationships. Basement membrane-specific HSPG was found as a node, which was also a potential biomarker for oocyte maturation in HFF. HSPG was widely distributed on the surface of animal cells, and especially strongly expressed in granulosa cells. HSPG played a critical role in controlling inflammation control through binding and activating antithrombin III during folliculogenesis [48]. Women with PCOS showed HSPG defect in follicular development [49], and on the contrary, HSPG was up-regulated in the fertilized-oocyte HFF [32]. In the network, HSPG interacted with 20 of 219 HFF proteins, and constructed 105 paired relationships. We deduced that the loss of HSPG might affect the function of the whole network or more complicated interaction maps, which might cause subsequent failures of oocyte maturation, fertilization, and IVF treatment.

\section{Conclusions}

HFF had a natural advantage for the noninvasive prediction of oocyte quality and IVF treatment outcome. The present study would provide a new complementary dataset for better understanding of oocyte maturation, and also delineate a new networks and pathways involved into the folliculogenesis. Furthermore, those novel findings would facilitate to testify the potential biomarkers associated with oocyte quality and IVF outcome. In the future, international laboratory collaboration should be established to standardize and optimize experimental design, patient selection, HFF handling, analysis methods, data standard, and clinical verification, which will greatly promote basic research of reproductive medicine, and ultimately accelerate the clinical transformation.

\section{Additional files}

Additional file 1: The information of antibodies and secondaries for Western blotting. (XLSX $10 \mathrm{~kb}$ )

Additional file 2: The overlap of known data and novel findings. (JPEG 1344 kb)

\section{Abbreviations}

2D-GE: Two-dimensional gel electrophoresis; A2M: Alpha-2-macroglobulin; BMI: Body mass index; C1qrs: Complement C1q A chain; C2: Complement C2; C3: Complement C3; C4: Complement C4; C4BP: C4b-binding protein alpha chain; C5: Complement C5; C6: Complement C6; C7: Complement C7; C8A: Complement component C8 alpha chain; C8B: Complement component C8 beta chain; C8G: Complement component C8 gamma chain; C9: Complement C9; CE: Capillary electrophoresis; $\mathrm{COH}$ : Controlled ovarian hyperstimulation; CPB2: Carboxypeptidase B2; DAVID: The database for annotation, visualization and integrated discovery; F10: Coagulation factor $X_{\text {; }}$ F12: Coagulation factor XII; F2: Prothrombin; F9: Coagulation factor IX; FB: Complement factor B; FDR: False Discovery Rate; FDR: False discovery rate; FGA: Fibrinogen alpha chain; FGB: Fibrinogen beta chain;

FGG: Fibrinogen gamma chain; FH: Complement factor $\mathrm{H}$; Fl: Complement factor l; HCG: Human chorionic gonadotrophin; HFF: Human follicular fluid; HSPG: Heparan sulfate proteoglycan core protein; IEF: Isoelectric focusing; IVF: In vitro fertilization; KEGG: Kyoto encyclopedia of genes and genomes; KLKB1: Plasma kallikrein; KNG1: Kininogen-1; MALDI TOF/TOF: Matrix-assisted laser desorption/ionization time-of-flight tandem; PANTHER: Protein analysis through evolutionary relationships; PCOS: Polycystic ovary syndrome; PLG: Plasminogen; PROC: Vitamin K-dependent protein C; PROS1: Vitamin Kdependent protein S; RP-HPLC: Reverse phase high performance liquid chromatography; SCX: Strong cation exchange; SDS-PAGE: One dimensional 
sodium dodecyl polyacrylamide gel electrophoresis; SELDI-TOF-MS: surfaceenhanced laser desorption/ionization-time of flight-mass spectrometry; SERPINA1: Alpha-1-antitrypsin; SERPINA5: Plasma serine protease inhibitor; SERPINC1: Antithrombin-III; SERPIND1: Heparin cofactor 2; SERPINF2: Alpha-2antiplasmin; SERPING1: Plasma protease C1 inhibitor; STRING: search tool for recurring instances of neighbouring genes; WCX: weak cation-exchange; WGOC: Working Group on Obesity in China

\section{Acknowledgements}

We thank Guo Lihai PhD (Shanghai Asia Pacific Application Support Center, Applied Biosystems, China) for the usage training of LC MALDI TOF/TOF 5800 mass spectrometer (AB SCIEX, USA).

\section{Funding}

The current study was supported by the National Natural Science Foundation of China (grant nos. 8130053381501313 and 81571490), Shandong Provincial Natural Science Foundation, China (grant nos. ZR2014HQ068 and ZR2015HQ031) and Yantai Science and Technology Program (grant no. 2015WS019, 2015WS024 and 2016WS001).

\section{Availability of data and materials}

The datasets used and/or analysed during the current study available fromthe corresponding author on reasonable request.

\section{Authors' contributions}

$\mathrm{XS}, \mathrm{XL}$, FL conceived of the study, participated in its design and coordination and reviewed the final manuscript for submission. PZ participated in the design of study, carried out the studies and drafted the manuscript. YZ, JW, YW, WW participated in the design of study, carried out the studies and helped to draft the manuscript. XL, FL, PZ performed the proteomic analysis. $J \mathrm{~L}, \mathrm{NL}$ carries out the bioinformatics analysis. XS participated in the study design and performed the HFF collection. All authors read and approved the final manuscript.

\section{Ethics approval and consent to participate}

This work has been approved by the Ethics Committee of Beijing BaoDao Obstetrics and Gynecology Hospital, and written informed consents were obtained from all participants.

\section{Consent for publication}

Not applicable.

\section{Competing interests}

The authors declare that they have no competing interests.

\section{Publisher's Note}

Springer Nature remains neutral with regard to jurisdictional claims in published maps and institutional affiliations.

\section{Author details \\ ${ }^{1}$ Central Laboratory, The Affiliated Yantai Yuhuangding Hospital of Qingdao University, Yantai 264000, Shandong, People's Republic of China. \\ ${ }^{2}$ Reproductive center, Beijing BaoDao obstetrics and gynecology hospital, Beijing 100000, People's Republic of China. ${ }^{3}$ Reproductive Medicine Centre, Wei fang people's hospital, Weifang, Shandong 261000, People's Republic of China.}

Received: 3 May 2017 Accepted: 19 July 2017

Published online: 27 July 2017

\section{References}

1. Steptoe PC, Edwards RG. Birth after the reimplantation of a human embryo. Lancet. 1978:2:366

2. Wang HB. Embryo implantation: progress and challenge. Chinese Bulletin of Life Sciences. 2017;29:31-42.

3. Kovalevsky G, Patrizio P. High rates of embryo wastage with use of assisted reproductive technology: a look at the trends between 1995 and 2001 in the United States. Fertil Steril. 2005;84:325-30.

4. Van Loendersloot LL, van Wely M, Limpens J, Bossuyt PMM, Repping S, der van Veen F. Predictive factors in vitro fertilization (IVF): a systematic review and meta-analysis. Hum Reprod Update. 2010;6:577-89.
5. Fortune JE. Ovarian follicular growth and development in mammals. Biol Reprod. 1994;50:225-32.

6. Zamah AM, Hassis ME, Albertolle ME, Williams KE. Proteomic analysis of human follicular fluid from fertile women. Clin Proteomics. 2015;3(5):1-12.

7. Guo N, Liu P, Ding J, Zheng SJ, Yuan BF, Feng YQ. Stable isotope labeling Liquid chromatography/mass spectrometry for quantitative analysis of androgenic and progestagenic steroids. Anal Chim Acta. 2016;905:106-14.

8. Xia L, Zhao X, Sun Y, Hong Y, Gao Y, Hu S. Metabolomic profiling of human follicular fluid from patients with repeated failure of in vitro fertilization using gas chromatography/mass spectrometry. Int J Clin Exp Pathol. 2014;7:7220-9.

9. Edwards RG. Follicular fluid. J Reprod Fertil. 1974;37:189-219.

10. Wu YT, Wang TT, Chen XJ, Zhu XM, Dong MY, Sheng JZ, et al. Bone morphogenetic protein-15 in follicle fluid combined with age may differentiate between successful and unsuccessful poor ovarian responders. Reprod Biol Endocrinol. 2012;10(116):1-6.

11. Benkhalifa M, Madkour A, Louanjli N, Bouamoud N, Saadani B, Kaarouch I, et al. From global proteome profiling to single targeted molecules of follicular fluid and oocyte: contribution to embryo development and IVF outcome. Expert Rev Proteomics. 2015;12:407-23.

12. Li L, Xing FQ, Chen SL, Sun L, Li H. Proteomics of follicular fluid in mature human follicles and antral follicles: a comparative study with laser desorption/ionization-time of flight-mass spectrometry. Nan Fang Yi Ke Da Xue Xue Bao. 2008;28(2):275-8.

13. Wu YT, Wu Y, Zhang JY, Hou NN, Liu AX, Pan JX, et al. Preliminary proteomic analysis on the alterations in follicular fluid proteins from women undergoing natural cycles or controlled ovarian hyperstimulation. J Assist Reprod Genet. 2015;32:417-27.

14. Ambekar AS, Nirujogi RS, Srikanth SM, Chavan S, Kelkar DS, Hinduja I, et al. Proteomic analysis of human follicular fluid: a new perspective towards understanding folliculogenesis. J Proteome. 2013;87:68-77.

15. Chen F, Spiessens C, D'Hooghe T, Peeraer K, Carpentier S. Follicular fluid biomarkers for human in vitro fertilization outcome: Proof of principle. Proteome Sci. 2016;14(17):1-11.

16. Zhou BF. Predictive values of body mass index and waist circumference to risk factors of related diseases in Chinese adult population. Zhonghua Liu Xing Bing Xue Za Zhi. 2002;23:5-10.

17. Zhou B. Coorperative Meta-Analysis Group of Working Group On Obesity In China. Prospective study for cut-off points of body mass indexin Chinese adults Zhonghua Liu Xing Bing Xue Za Zhi. 2002;23:431-4.

18. Zhou BF. Predictive values of body mass index and waist circumference for risk factors of certain related diseases in Chinese adults-study on optimal cut-off points of body mass index and waist circumference in Chinese adults. Biomed Environ Sci. 2002;15:83-96.

19. Huang $X$, Hao C, Shen X, Liu X, Shan Y, Zhang Y, et al. Differences in the transcriptional profiles of human cumulus cells isolated from MI and MII oocytes of patients with polycystic ovary syndrome. Reproduction. 2013;145:597-608.

20. Gotham SM, Fryer PJ, Paterson WR. The measurement of insoluble proteins using a modified Bradford assay. Anal Biochem. 1988;173:353-8.

21. Ding C, Jiang J, Wei J, Liu W, Zhang W, Liu M, et al. A fast workflow for identification and quantification of proteomes. Mol Cell Proteomics. 2013;12:2370-80.

22. Sun W, Xing B, Guo L, Liu Z, Mu J, Sun L, et al. Quantitative Proteomics Analysis of Tissue Interstitial Fluid for Identification of Novel Serum Candidate Diagnostic Marker for Hepatocellular Carcinoma. Sci Rep. 2016;24:26499.

23. Mi H, Muruganujan A, Casagrande JT, Thomas PD. Large-scale gene function analysis with the PANTHER classification system. Nat Protoc. 2013;8:1551-66.

24. Huang da W, Sherman BT, Lempicki RA. Systematic and integrative analysis of large gene lists using DAVID bioinformatics resources. Nat Protoc. 2009;4:44-57.

25. Kanehisa M, Furumichi M, Tanabe M, Sato Y, Morishima K KEGG: new perspectives on genomes, pathways, diseases and drugs. Nucleic Acids Res. 2017;45:D353-61.

26. Szklarczyk D, Franceschini A, Wyder S, Forslund K, Heller D, Huerta-Cepas J, et al. STRING v10: protein-protein interaction networks, integrated over the tree of life. Nucleic Acids Res. 2015;43:D447-52.

27. Liu X, Wang W, Liu F. New insight into the castrated mouse epididymis based on comparative proteomics. Reprod Fertil Dev. 2015;27:551-6.

28. Liu J, Zhu P, Wang WT, Li N, Liu X, Shen XF, et al. TAT-peroxiredoxin 2 Fusion Protein Supplementation Improves Sperm Motility and DNA Integrity in Sperm Samples from Asthenozoospermic Men. J Urol. 2016;195:706-12.

29. Farrah T, Deutsch EW, Omenn GS, Campbell DS, Sun Z, Bletz JA, et al. A high-confidence human plasma proteome reference set with estimated concentrations in PeptideAtlas. Mol Cell Proteomics. 2011;10:M110.006353. 
30. Lo Turco EG, Cordeiro FB, Lopes PH, Gozzo FC, Pilau EJ, Soler TB, et al. Proteomic analysis of follicular fluid from women with and without endometriosis: new therapeutic targets and biomarkers. Mol Reprod Dev. 2013:80:441-50.

31. Twigt JM, Bezstarosti K, Demmers J, Lindemans J, Laven JS, SteegersTheunissen RP. Preconception folic acid use influences the follicle fluid proteome. Eur J Clin Investig. 2015;45:833-41.

32. Bayasula IA, Kobayashi H, Goto M, Nakahara T, Nakamura T, et al. A proteomic analysis of human follicular fluid: comparison between fertilized oocytes and non-fertilized oocytes in the same patient. J Assist Reprod Genet. 2013;30:1231-8.

33. Hanrieder J, Zuberovic A, Bergquist J. Surface modified capillary electrophoresis combined with in solution isoelectric focusing and MALDITOF/TOF MS: a gel-free multidimensional electrophoresis approach for proteomic profiling-exemplified on human follicular fluid. J Chromatogr A. 2009;1216:3621-8.

34. Hanrieder J, Nyakas A, Naessén T, Bergquist J. Proteomic analysis of human follicular fluid using an alternative bottom-up approach. J Proteome Res. 2008;7:443-9.

35. Von Wald T, Monisova Y, Hacker MR, Yoo SW, Penzias AS, Reindollar RR, et al. Age-related variations in follicular apolipoproteins may influence human oocyte maturation and fertility potential. Fertil Steril. 2010;93:2354-61.

36. Levi M, van der Poll T, Büller HR. Bidirectional relation between inflammation and coagulation. Circulation. 2014;109:2698-704.

37. Ricklin D, Hajishengallis G, Yang K, Lambris JD. Complement: a key system for immune surveillance and homeostasis. Nat Immunol. 2010;11:785-97.

38. Ghebrehiwet B, Silverberg M, Kaplan AP. Activation of the classical pathway of complement by Hageman factor fragment. J Exp Med. 1981;153:665-76.

39. Huber-Lang M, Sarma JV, Zetoune FS, Rittirsch D, Neff TA, McGuire SR, et al. Generation of $\mathrm{C} 5 \mathrm{a}$ in the absence of C3: a new complement activation pathway. Nat Med. 2006;12:682-7.

40. de Agostini Al, Dong JC, de Vantéry AC, Ramus MA, DentandQuadri I, Thalmann S, et al. Human follicular fluid heparan sulfate contains abundant 3-O-sulfated chains with anticoagulant activity. J Biol Chem. 2008;283: 28115-24

41. Ebisch IM, Thomas CM, Wetzels AM, Willemsen WN, Sweep FC, SteegersTheunissen RP. Review of the role of the plasminogen activator system and vascular endothelial growth factor in subfertility. Fertil Steril. 2008;90:2340-50.

42. Espey LL. Current status of the hypothesis that mammalian ovulation is comparable to an inflammatory reaction. Biol Reprod. 1994;50:233-8.

43. Girardi G, Salmon JB. The role of complement in pregnancy and fetal loss. Autoimmunity. 2003;36:19-26.

44. Girardi G. Complement inhibition keeps mothers calm and avoids fetal rejection. Immunol Investig. 2008;37:645-59.

45. Jarkovska K, Martinkova J, Liskova L, Halada P, Moos J, Rezabek K, et al. Proteome mining of human follicular fluid reveals a crucial role of complement cascade and key biological pathways in women undergoing in vitro fertilization. J Proteome Res. 2010:9:1289-301.

46. Richani K, Soto E, Romero R, Espinoza J, Chaiworapongsa T, Nien JK, et al. Normal pregnancy is characterized by systemic activation of the complement system. J Matern Fetal Neonatal Med. 2005;17:239-45.

47. Gonzales J, Lesourd S, van Dreden P, Richard P, Lefebvre G, Brouzes DV. Protein composition of follicular fluid and oocyte cleavage occurrence in in vitro fertilization (IVF). J Assist Reprod Genet. 1992;9:211-6.

48. de Agostini A. An unexpected role for anticoagulant heparan sulfate proteoglycans in reproduction. Swiss Med Wkly. 2006;136:583-90

49. Ambekar AS, Kelkar DS, Pinto SM, Sharma R, Hinduja I, Zaveri K, et al. Proteomics of follicular fluid from women with polycystic ovary syndrome suggests molecular defects in follicular development. J Clin Endocrinol Metab. 2015;100:744-53.

\section{Submit your next manuscript to BioMed Central and we will help you at every step:}

- We accept pre-submission inquiries

- Our selector tool helps you to find the most relevant journal

- We provide round the clock customer support

- Convenient online submission

- Thorough peer review

- Inclusion in PubMed and all major indexing services

- Maximum visibility for your research

Submit your manuscript at www.biomedcentral.com/submit 